\title{
JURISPRUDENCIA AMBIENTAL EN CASTILLA Y LEÓN (SEGUNDO SEMESTRE 2017)
}

\author{
IÑIGO SANZ RUBIALES \\ Catedrático de Derecho Administrativo \\ Universidad de Valladolid
}


Sumario: 1. Introducción. 2. Anulación parcial del Decreto de especies cinegéticas. 3. De nuevo sobre la ciudad del medio ambiente: la invocación de la "fuerza normativa de lo fáctico". 4. Las posibilidades legitimatorias en materia ambiental. 5. Sobre las diferencias entre licencias de obras y de actividad. La tolerancia de una actividad sin licencia no implica su autorización implícita.

\section{Introducción}

La actividad judicial de este segundo semestre de 2017 en el Tribunal Superior de Justicia de Castilla y León nos aporta interesantes resoluciones de recursos directos contra reglamentos: el proyecto (material y formalmente degradado) de la Ciudad del Medio Ambiente en Soria, todavía polémico, y el también discutido Decreto de especies cinegéticas. Se comentan, además, otras sentencias sin ese alcance normativo, pero que resuelven cuestiones con elevado interés conceptual jurídico-ambiental.

\section{Anulación parcial del decreto de especies cinegéticas}

La STSJ Castilla y León (Valladolid) de 17 de mayo de 2017 (Rec. 615/2015) viene a resolver un recurso directo contra el Decreto no 32/2015, de 30 de abril, de la Junta de Castilla y León, por el que se regula la conservación de las especies cinegéticas de Castilla y León, su aprovechamiento sostenible y el control poblacional de la fauna silvestre. Es recurrente una organización ecologista y demandada la Junta de Castilla y León y la Federación de Caza de idéntico ámbito territorial.

Han sido varios los Decretos relativos a especies cinegéticas impugnados en los últimos lustros y anulados, total o parcialmente. De hecho, por Sentencia de 2 de febrero de 2015 fue anulado el Decreto 65/2011, de 23 de noviembre, por el que se regulaba la conservación de las especies cinegéticas de Castilla y León, su aprovechamiento sostenible y el control poblacional de la fauna silvestre, por falta de informe del Consejo Regional de Medio Ambiente que fue sustituido por el vigente Decreto 32/2015, ahora impugnado.

Los recurrentes impugnan diversos preceptos de este Decreto de 2015; algunas de las peticiones fueron desestimadas. La estimación de otras llevó a la anulación parcial del Decreto, en diversos aspectos que merece la pena destacar: 
-Se denuncia -entre otras cosas- que la modalidad de caza de palomas en pasos tradicionales, y la caza de acuáticas desde puestos fijos, deben contemplarse específicamente, sin que pueda remitirse la concreción de dicha regulación a un Plan de caza posterior, como hace el Decreto.

El Tribunal, en línea con otras sentencias anteriores, entiende que esta ausencia de regulación en el Decreto permite que "cuestiones que deben ser fijadas por una norma reglamentaria dotada del rango y estabilidad precisas sean reguladas por simples órdenes anuales". Por este motivo, estima el recurso en este punto y declara la nulidad del art. 9.4 en el apartado correspondiente. Merece la pena recordar -y así lo hace la sentencia- que la STSJ de 28 de febrero de 2012 anuló la Orden 928/2010, anual de caza, por invadir ámbitos competenciales propios del reglamento, y señalaba al respecto: "Es parecer de este Tribunal que una y otra exigencia legal requiere un tratamiento normativo propio, específico y de carácter estable que un acto de naturaleza ordinamental y temporal como es la denominada orden anual de caza no puede llegar a satisfacer. Cuando esas disposiciones legales emplean los vocablos "reglamentariamente" y "previa regulación reglamentaria" imponen un tratamiento de carácter normativo permanente y previo a otra actuación con funcionalidad diferente como es la orden de caza".

-Se impugna también el art. 13 del Decreto, en cuanto que declara cinegéticas una serie de especies de caza mayor y menor "de acuerdo con la definición del art. 1.2" del mismo Decreto. Y este art. 1.2 define, en consonancia con el art. 7 de la Directiva de Aves Silvestres, las especies cinegéticas sobre la base de tres criterios: son especies que (i) no se encuentran en ninguno de los supuestos de protección estricta conforme a la normativa comunitaria, estatal y autonómica, (ii) gozan de interés por parte del colectivo de cazadores, y (iii) debido a sus niveles poblacionales, distribución geográfica e índice de reproductividad, pueden soportar una extracción ordenada de ejemplares sin que ello comprometa su estado de conservación en su área de distribución. Pues bien, señala la sentencia, eso implica que "la determinación de las especies susceptibles de caza y la fijación de los periodos hábiles para ello 
requieren la realización de estudios previos de referencia específicos, para lograr adecuarlos al aprovechamiento sostenible de las mismas". Y en concreto, los demandantes muestran cómo, según los datos de estudios realizados por la SEO Birdlife, hay cuatro especies en claro descenso (Tórtola europea, codorniz, perdiz roja y grajilla). Y cita la STSJ Castilla-La Mancha de 24 de enero de 2011, recurso n 776/2007, para recordar que "no se puede autorizar la caza de esas especies sin haber acreditado previamente el buen estado de conservación de las mismas". En definitiva, "el hecho de que una especie esté recogida en el anexo II no obliga a un Estado miembro a autorizar que sea objeto de caza. Se trata sólo de una posibilidad de la que los Estados miembros pueden hacer uso o no en función de las características y condiciones propias de cada especie en su territorio". De acuerdo con esta clara argumentación, se anula el citado art. 13.

-También se impugna el art. 14. El Decreto, tras declarar en el art. 13 las especies cinegéticas, en el 14 remite la determinación de las especies cinegéticas que serán cazables a las Órdenes Anuales de Caza. Esta previsión -entiende la sentencia- es contraria a la Directiva Aves silvestres porque esa concreción, de acuerdo con el principio de "utilización razonable", no puede venir determinada por normas administrativas temporales de vigencia anual como son las Ordenes de caza. Es decir, la Orden Anual de Caza (según el art. 41 de la Ley de Caza de 1996) podrá determinar las especies cazables cada temporada pero para ello es preciso que previamente se haya establecido un régimen de protección de dichas especies de modo que se garantice su estado de conservación, y su utilización razonable, y esta función la debe llevar a cabo una norma de duración indeterminada y de contenido cinegético y ambiental, como el Decreto impugnado, y no una Orden de Caza, de duración determinada y contenido exclusivamente cinegético. Por los citados motivos, se anula el art. 14.

Finalmente se impugna, y también es anulado, el art. 15, en cuanto que permite a los Agentes forestales autorizar excepcionalmente la caza en días de fortuna y en días en que el terreno esté cubierto de nieve. Se anula porque la Ley 
4/1996, de Caza, no establece ninguna excepción a la prohibición, por lo que el Reglamento de desarrollo no puede generarla.

Finalmente, se anula también el art. 19 nำ a), c) y d), en cuanto que permite realizar controles poblacionales de determinadas especies (urraca, y corneja, jabalí y otros ungulados silvestres y lobo) en época de cría.

En definitiva, se anulan varios preceptos, por la excesiva remisión a las órdenes anuales de caza, por la ausencia de estudios necesarios, por la posibilidad de autorizar la caza en días de fortuna o de realizar controles poblacionales en determinadas épocas de cría. $Y$ el punto de referencia constante es la Directiva Aves Silvestres (DAS, como la nombra la sentencia), la Ley de Caza y una abundante jurisprudencia de la misma Sala que viene insistiendo en los mismos argumentos.

3. De nuevo sobre la ciudad del medio ambiente: la invocación de la "fuerza normativa de lo fáctico"

Como es sabido, la Comunidad Autónoma, para "blindar" el Proyecto urbanístico de la Ciudad del Medio Ambiente de Soria, dispuso su aprobación por Ley singular, la Ley 6/2007, de 28 de marzo que, sin embargo, fue posteriormente declarada inconstitucional por STC 203/2013, de 5 de diciembre. Ahora bien, durante la efímera vigencia de la Ley se urbanizó el $77 \%$ del Sector 1 del proyecto, inclusivo de las redes básicas de servicios, y el sector 2 en su totalidad; ahí está instalada y funcionando la central de biomasa. Una vez publicada la sentencia del Tribunal Constitucional, la Administración autonómica procedió a elaborar un Decreto de aprobación del Proyecto regional, ajustándolo a la situación fáctica del viejo proyecto y reduciendo el ámbito territorial de este a poco mas de un 25\% del terreno original. Suprimió los usos residenciales y mantuvo los industriales y, específicamente, la central de biomasa en funcionamiento.

Esta sentencia del TSJ Castilla y León (Burgos) de 29 de mayo de 2017 (rec. $67 / 2015)$ viene a resolver la impugnación del Decreto 18/2015 de la Consejería 
de Fomento y Medio Ambiente de la Junta de Castilla y León de 26 de febrero de 2015, por el que se aprueba el Proyecto Regional "Parque Empresarial del Medio Ambiente" en el término municipal de Garray (Soria).

El núcleo argumental del recurso se centra en la condición urbanística del suelo del proyecto. Con la anulación operada por el Tribunal Constitucional, recuperan su vigencia las Normas Subsidiarias de Garray de 1993, que calificaban la mayor parte del suelo ocupado por el Proyecto Regional (salvo 31 hectáreas) como suelo no urbanizable de especial protección. Por lo tanto, según los recurrentes, "el suelo comprendido en el proyecto y ordenado no cumple con la condición de suelo urbano" "porque no se integra en la malla urbana a que se refiere el art. 23 del RUCyL al estar separado del suelo urbano y tratarse de una zona de nueva implantación; porque también infringe lo dispuesto en el art. 27 del RUCyL para su clasificación como suelo urbanizable por cuanto no se considera justificada su clasificación a la vista de las demandas de dicho suelo y porque que no es colindante al menos en un $20 \%$ con el suelo urbano del núcleo de población existente; y porque tampoco han desaparecido las causas que dieron lugar a la clasificación de tales terrenos en 1993".

Frente a esta petición y argumentación, la Sala se muestra pragmática, pegada al terreno, y poco partidaria de demoler lo construido y que está en funcionamiento.

En primer lugar (FD 9o), la Sala trae a colación la doctrina del Tribunal Constitucional sobre la base del art. 40 LOTC y de la Jurisprudencia contencioso-administrativa para determinar que "el desarrollo y la gestión urbanística (urbanización y reparcelación) realizada en el ámbito espacial del Proyecto Regional "Ciudad del Medio Ambiente" en aplicación de los instrumentos urbanísticos aprobados en desarrollo de la Ley 6/2007, luego declarada inconstitucional, instrumentos que no fueron objeto de anulación judicial, ha permitido que el suelo inicialmente comprendido en el Proyecto Regional de la Ciudad del Medio Ambiente, ahora comprendido en el Proyecto Regional "Parque Empresarial del Medio Ambiente" haya pasado a ser un 
suelo urbano por cuanto que tales terrenos, tras su urbanización, se han integrado de forma legal y efectiva en la red de dotaciones y servicios de un núcleo de población", de tal forma que la posterior declaración de inconstitucionalidad de la Ley que daba cobertura legal a tales instrumentos de gestión urbanística (...) que devinieron en actuaciones administrativas firmes antes de dicha declaración de inconstitucionalidad, no permite, de conformidad con la Jurisprudencia reseñada, revisar tales procesos". La Sala asume así la justificación derivada de la "fuerza normativa de lo fáctico", consagrada por la jurisprudencia para clasificar suelo urbano, argumentación que esgrimió la Comunidad Autónoma en la Exposición de Motivos de dicho Decreto; dicha realidad urbanística es "consecuencia de haberse ejecutado casi en su totalidad sendos proyectos de actuación que habían sido tramitados y aprobados para dicho suelo cuando quedaban comprendidos en el Proyecto Regional de la Ciudad del Medio Ambiente".

Igualmente (FD 11), rechaza la no calificación de suelo urbano que aporta la demanda, porque, aunque falta la necesaria colindancia del $20 \%$, exigida por el art.13 de la LUCyL y el art. 27.2 del RUCyL lo cierto es que puede acogerse a las excepciones previstas en sendos preceptos y que permiten su calificación como urbano: el uso predominante del sector no es el residencial, sino el industrial, y está previsto en un instrumento de ordenación del territorio. "Concurriendo estas dos últimas excepciones no se exige en dicha clasificación la colindancia en al menos un $20 \%$ con el suelo urbano de un núcleo de población existente".

Además, justifica la integración de dicho suelo en la malla urbana, a la luz de las previsiones de la DIA, relativas a los servicios urbanísticos, que va enumerando uno por uno para demostrar que se cumple dicha integración.

Finalmente, entiende la Sala justificada la intervención realizada a la luz de la documentación aportada por la Administración promotora (FD 12).

En definitiva: "peor es meneallo"; dejemos lo que está (actuaciones administrativas firmes a la hora de emitir su sentencia el Constitucional), 
evitemos males mayores demoliendo actuaciones que son viables y pueden ser ambiental y socialmente positivas y protejamos, eso sí, el resto del espacio que no ha sido objeto de ejecución urbanística.

\section{Las posibilidades legitimatorias en materia ambiental}

El asunto que se ventila en esta sentencia del TSJ Castilla y León (Valladolid) de 2 de mayo de 2017 (Rec. 1329/2014) versa sobre la impugnación, realizada por una empresa de gestión de residuos, de la inadmisión de una previa solicitud de revisión de oficio de la Orden de 17 de diciembre de 2008 de la Consejería de Medio Ambiente por la que se concede autorización ambiental al Excmo. Ayuntamiento de Valladolid para Planta de Recuperación y Compostaje de residuos urbanos y Vertedero de residuos no peligrosos y del recurso de reposición contra la Orden FYM/362/2014 de 30 de abril, por la que se declara que procede iniciar la actividad en dicha Planta de Recuperación y Compostaje de residuos urbanos y Vertedero de residuos no peligrosos.

El motivo de fondo de la impugnación es que la Planta recibe residuos que no son urbanos sin tener autorización para ello, y no se exigió Evaluación Ambiental para la concesión de la autorización ambiental correspondiente. La Sala lo resuelve de forma sencilla, porque se demuestra que sí existió Evaluación Simplificada de Impacto Ambiental, conforme a la normativa autonómica aplicable en su momento (FD $2^{\circ}$ ), y por otra parte, afirma que no se ha aportado prueba alguna por la recurrente de la manifestación contenida en la demanda referida a que el Ayuntamiento en la Planta autorizada reciba residuos no urbanos sin tener la preceptiva autorización para ello (FD 4ํㅜ).

Pero mas interés tiene, aquí, la argumentación relativa a la legitimación del demandante. Este alega, para justificar la existencia de un interés legítimo, que pertenece al sector afectado por los actos impugnados y ha suscrito un contrato de arrendamiento de una finca sita en Villanubla (Valladolid) para desarrollar la actividad de "gestión de residuos industriales no peligrosos y acopio de materiales" (FD $1^{\circ}$ ), y que "su interés va más allá de la simple legalidad, y que se trata de un interés competitivo o profesional conectado 
siempre con el perjuicio de contenido económico" (FD $2^{\circ}$ ). La Sala trae a colación la reiterada jurisprudencia del Tribunal Supremo, según la cual "para que exista interés legitimador basta con que el éxito de la acción signifique para el recurrente un beneficio material o jurídico o, por el contrario, que el mantenimiento de la situación creada por el actor combatido le origine un perjuicio, incluso aunque tales beneficios o perjuicios se produzcan por vía indirecta o refleja" (FD $3^{\circ}$ ). Siguiendo esta jurisprudencia, distingue entre interés directo e interés legítimo y afirma la necesidad de un análisis casuístico de la legitimación.

De acuerdo con lo anterior, va desgranando los diversos elementos de la legitimación; por una parte, afirma que el alegado interés competitivo profesional no es tal, porque se ubica en ámbitos materiales distintos (el del impugnante, en los residuos industriales no peligrosos y acopio de materiales y el otro en los denominados residuos urbanos); niega la aplicación de la acción popular prevista en la Ley 16/2002, de Prevención y Control Integrados de la Contaminación (art. 3.17. $2^{\circ}$ ), que se otorga a las organizaciones ambientalistas con coincidencia de objeto estatutario, ámbito territorial y con dos años de existencia; y, finalmente, demuestra la inaplicabilidad de la acción pública prevista en el art. 88 de la Ley de Prevención Ambiental de Castilla y León (Texto Refundido aprobado por Decreto Legislativo 1/2015) porque es aplicable únicamente en materia sancionadora.

De todo lo expresado por la sentencia, debe cuestionarse la "ausencia de legitimación por no existir interés competitivo", porque, a la luz de lo afirmado por el demandante, dicho interés competitivo existe, si es verdad que el vertedero del Ayuntamiento no se limitar a recibir residuos urbanos sino también los industriales no peligrosos, objeto de la actividad del demandante. Aunque, por otra parte, si fuese cierta esta recepción, eso no obstaría a la validez de la autorización concedida: no hay que olvidar que la invalidez radical (nulidad de pleno derecho) es originaria y que el incumplimiento del condicionado de la autorización puede implicar la revocación de esta pero nunca su nulidad de pleno derecho. 


\section{Sobre las diferencias entre licencias de obras y de actividad. La tolerancia de una actividad sin licencia no implica su autorización implícita}

Se impugna en este recurso, que resuelve la STSJ Castilla y León (Burgos) de 28 de abril de 2017 (Rec. 11/2017), la resolución de la Junta de Gobierno Local del Ayuntamiento de Navas de Oro de 26 de febrero de 2016, por la que se concluye que una explotación porcina no tiene licencia de apertura, o licencia de actividad o licencia ambiental, y se acuerda el cese definitivo de dicha explotación ganadera.

La historia del asunto comienza con denuncias de la Guardia Civil y de particulares que permiten al Ayuntamiento abrir diligencias previas a la posible incoación de un procedimiento de restauración de la legalidad. Iniciado, posteriormente, dicho procedimiento, el 11 de diciembre de 2015, la Junta de Gobierno Local del Ayuntamiento requiere al titular para legalizar la actividad realizada en la explotación sin licencia ambiental en el plazo de dos meses. Finalmente, tras rechazar las alegaciones correspondientes, se declara que la instalación carece de licencia de apertura o licencia de actividad o licencia ambiental, y se acuerda el cese definitivo de la actividad, lo que se notifica con fecha 2 de marzo de 2016.

El recurrente, en primera y segunda instancia, alega, por una parte, caducidad del procedimiento y, por otra, la titularidad de las correspondientes licencias de actividad, otorgadas en 1963 y 1988.

La Sala desmonta ambos argumentos; por una parte, la caducidad, atendiendo, no a los términos utilizados por la Administración municipal (que "inicia" el procedimiento de regularización en dos ocasiones) sino a los trámites reales, distingue entre actuaciones previas (que no forman parte de un procedimiento formal y, por tanto, no están sometidas a la caducidad-perención) y procedimiento de restauración sensu stricto, que se incoa el 11 de diciembre de 2015 y se resuelve (notificado) el 2 de marzo de 2016, antes de los tres meses de rigor. El dies a quo de la caducidad-perención es el de la incoación del 
procedimiento y esta incoación se produjo en diciembre y no antes, porque los trámites anteriores se debían calificar como diligencias previas (FD 2º$)$.

En cuanto al fondo, hay que recordar que, en 1963, el RAMINP llevaba escasos meses en vigor, por lo que la Sala analizó la documentación aportada al expediente para diseccionar los trámites del procedimiento de autorización de cebadero (1963) y, posteriormente, de colgadizo (1988). Tras analizar la normativa aplicable y la documentación, la Sala concluye que la licencia para cebadero otorgada el día 4.3.1963 y la licencia para la instalación de colgadizo concedida en el año 1988 no constituyen una verdadera licencia de actividad, ni ambiental ni de apertura: estamos ante una actividad (explotación porcina, cebadero) que necesita licencia pero en la que la actividad de control por la Administración es continua: no cesa con la apertura, ni mucho menos, sino que se debe mantener constantemente durante el desarrollo de la actividad.

En efecto, es evidente que la licencia para la construcción del colgadizo es una licencia de obras, porque así se deduce de los propios términos de la licencia; pero el Tribunal tuvo que analizar, sin embargo, la naturaleza de la licencia de cebadero. En relación con esta, concluye la Sala, "no consta que se cumpliera los trámites exigidos para este tipo de licencias en los arts. 29 a 37 del RAMPIN (...), no consta que en relación con dicha solicitud se acompañara proyecto y memoria en la que se describiera la actividad a desarrollar y su extensión, que se abriera un trámite de información pública, que se notificara tal solicitud a los vecinos inmediatos al lugar de emplazamiento propuesto, que se emitiera informe por el Jefe Local de Sanidad y los técnicos municipales competentes, tampoco por la Corporación; tampoco consta que dicha solicitud y mencionado expediente fuera remitido para su información a la Comisión Provincial a que se refiere el art. 31 y siguientes del RAMINP, como tampoco consta que se girara la vista de comprobación e inspección previa a iniciarse la actividad a que se refieren los arts. 34 y siguientes del RAMINP; por tanto no habiéndose aportado proyecto ni memoria y no habiéndose llevado a cabo ninguno de los tramites reseñados (...) esta Sala debe concluir que la licencia municipal para la instalación de cebadero de ganado otorgada el 28 de febrero de 1.993 no tiene la naturaleza de la licencia de instalación de actividad 
calificada como molesta, insalubre o nociva a que refiere el citado RAMINP, por cuanto que la solicitud, tramitación y concesión de aquella licencia no se ha efectuado según las preceptivas prescripciones del RAMINP" (FD 6º).

En definitiva, la metodología utilizada por la Sala es la correcta: el análisis del procedimiento, sus garantías en el orden medioambiental, es determinante para saber si la resolución es una autorización puntual (de obras) o una autorización de funcionamiento o de tracto sucesivo (de actividad).

No deja de llamar la atención, sin embargo, la tolerancia de la actividad; resulta sorprendente que una actividad cuyo carácter molesto, insalubre y nocivo es evidente (una granja porcina con capacidad para 1700 cerdos o "unidades porcinas") haya sido tolerada durante mas de medio siglo. Y así lo hace notar la sentencia: "dicha explotación se ha llevado a cabo con consentimiento, a vista y paciencia no solo del Ayuntamiento de Navas de Oro sino también del resto de administraciones y autoridades que conocían la existencia y funcionamiento de dicha explotación". "Pero no obstante lo dicho, -concluye la Sala- la concurrencia de tales extremos y circunstancias no conlleva ni supone que dicha explotación se encontrase amparada por la preceptiva licencia ambiental y de apertura": de acuerdo con la doctrina del Tribunal Supremo, "la mera tolerancia municipal que ha permitido ese funcionamiento a lo largo del tiempo no permite considerar que dichas licencias se han obtenido implícitamente". (FD $7^{\circ}$ ). 